\title{
Cloze Procedure in the Teaching of Reading
}

Patricia Raymond

Many teachers in both first language and second language classrooms adopt the cloze procedure. The cloze procedure is here defined as those rational deletions made by the teacher with the hope of teaching something in reading. The fact that the cloze procedure "works", has a "mechanical simplicity", "is simple and straightforward", and "does not involve experts or difficult administrative judgments" (Taylor, 1953: 432.) has a great deal of appeal for the experienced and novice teacher alike. However, many teachers do not realize that the cloze procedure is very deceptive in its simplicity. The undifferentiated use of the cloze procedure in a first or second language classroom in the hopes of some kind of reading improvement is very dubious (Jongsma, 1980: 15) and is termed the 'shotgun approach' (Jongsma, 1980: 25). Teachers must understand why the cloze procedure can be used to teach reading. Its effective classroom implementation depends on careful text selection, preparation and presentation.

\section{Rationale}

The cloze procedure can be used to teach reading because it goes beyond the sampling, reconstructing and matching demands of normal reading (Rye, 1982: 7). The reader not only reads the text but must also produce a word to fit a given context. The cloze procedure requires a search of a distribution of elements for the missing element. This search for the missing words is neither logical nor exhaustive because of imposed time constraints (Weaver, 1965: 127). The cloze procedure forces readers outside the sentence and interrupts their normal flow of reading. This use of information across sentence boundaries is an important aspect of reading comprehension, for it helps readers to recognize the interrelationships of language and to develop an awareness of sequence, both of which could help prediction. It also forces readers to reconstruct on the basis of a wider range of context cues, for they have to read beyond the unknown word for additional cues (Bortnick and Lopardo, 1973: 297). This reconstruction is at a more conscious level than in normal reading and could help to create an awareness of syntax and meaning. Matching is accomplished moreso on the basis of meaning than on information from graphics simply because 
of the missing words. It is a different kind of matching when compared with normal reading (Rye, 1982: 7).

The cloze procedure offers help in developing scanning and search reading skills which are very often neglected in both first and second language reading. ${ }^{1}$ (Rye, 1982: 45). More importantly, it helps readers to predict and provides practice in guessing meaning from context. Guessing meaning from context is an important reading strategy. ${ }^{2}$ While it is true that this strategy and its use are highly variable even for native speakers, for second language students, there will be many more new vocabulary items to contend with and training in guessing meaning from context becomes even more important. Van Parreren and Schouten-Van Parreren (1981) have found that guessing meaning from context is a trainable reader strategy in spite of its variability. In essence, for second language readers, all unmutilated texts resemble cloze texts because the unknown vocabulary words represent blanks for them.

Thus, it can be seen that the skills necessary to "cloze" a text, even though they go beyond the demands of normal reading, are comparable to those necessary for reading. Teaching cloze strategies is, in effect, teaching reading strategies.

\section{Text Selection}

When selecting a text for the cloze procedure, the teacher should carefully consider two issues. Firstly, the text should be worth reading and should contain material of value to the students (Marino, 1981). Secondly, the text should be suitable in terms of language difficulty. If it is beyond the independent reading level of the students before deletions are made, using it as a cloze exercise can only lead to frustration because the teacher is taking a text that is already too difficult for students and compounding this difficulty by making it into a cloze exercise. For this reason, the use of the cloze procedure to teach reading is not recommended for beginning and low intermediate proficiency ESL students.

\section{Text Preparation}

Cloze exercises require careful preparation. A successful cloze exercise will have at least 30 deletions (Bachman, 1985). The teacher sequences and selects the form of these deletions. The sequencing should begin with the rational deletion of one out of ten words and slowly progress to one out of five words. The teacher can change rational deletions to random after a certain time has elapsed. The deletion types will have prompts (visual cues) at first, e.g. 'sit----' or 's-----g' or the blank will correspond to the length of the deleted word (Rankin, 1977).

Rye (1982) states that the word to be deleted must be predictable and 
related to the purposes of instruction. More frequent structure words are easier to predict than content words. Beginning deletions should therefore be predominantly structure words.

Rankin (1977) suggests beginning with the rational deletions of structural words with prompts, then lexical entries with prompts, and then random deletions with prompts before moving to structural, lexical and random deletions without prompts.

Rye (1982: 70) includes the following guidelines for teachers to use when preparing a cloze exercise:

- is the deletion a structure or a content word?

- if it is a structure word, is it chosen to contribute to the ease of the task?

- if it is a content word, can it reasonably be inferred given the overall context and the students' general knowledge?

- if it is either a noun or a verb, have too many nouns and verbs already been deleted?

- does the position of the deletion make the task too difficult?

He also cautions that words deleted from the beginning of a sentence are harder to predict than those deleted from either the middle or the end.

Rankin (1977) suggests that teachers also sequence response types, i.e., from multiple choice alternatives to open cloze in which students supply the deleted word from memory. The multiple choice alternatives can begin with choices from different semantic and different grammatical classes, move to those from different semantic but the same grammatical class, continue to those with the same meaning but from a different grammatical class and finally end using alternatives with the same meaning from the same grammatical class.

An example of a cloze exercise deleting structural words without prompts follows (from Grellet, 1981: 49):

Instructions to students: Read the following text and select the most appropriate words from the list given below.

A color consultant from Toronto explained to the Inter-Society Color Council meeting in New York an ingenious scheme which a client company had conceived for increasing the sale of potato peelers. He began by pointing out a puzzling fact. (1) potato peelers 'never wear out', enough are sold in two years in this country to put one in every home. What happens to them? He gave this answer. "Investigation reveals that they get thrown away with the potato peelings". One of his colleagues, he added, had then come up with a dazzling plan for helping along this throw-away process. He proposed that their company paint their peelers "as much like a potato peeling as possible". a potato-colored peeler wouldn't have much eye-appeal on the sales counter. They decided to solve that by displaying the peeler on 
a colorful card. Once the housewife brought the peeler home and removed the bright card, the chances that she would lose the peeler were excellent.

In some cases, the consumers have no choice but to be wastemakers (3) the way products are sold to them. Many paste-pots come with brushes built into the cover, and the brushes fail by a half-inch to reach the bottom. (4) millions of 'empty' paste jars are thrown away with a few spoonfuls of paste still in them. (5) millions of 'used' tubes of lipstick are thrown away with a half-inch of lipstick remaining in the tube.
1. a. because
b. although
c. for example
d. since

2. a. in addition

b. on the contrary

c. in this way

d. however

3. a. in spite of

b. because of

c. as

d. in addition to
4. a. similarly

b. for example

c. however

d. thus (= in this way)

5. a. likewise (= similarly)

b. on the contrary

c. yet

d. for instance

A variation in the cloze procedure is found in Hoffman's cumulative cloze (1980), a modified cloze procedure in which the same word is deleted from a short passage and is replaced by a nonsense word (cited in Grellet, 1981: 32):

ZIP was stopped during the war and only after the war did it become popular. What a difference it has made to our lives. It keeps people at home much more. It has made the remote parts of the world more real to us. Photographs show a country, but only ZIP makes us feel that a foreign country is real. Also we can see scenes in the street; big occasions are ZIPPED such as the Coronation in 1953 and the Opening of Parliament. Perhaps the sufferers from ZIP are the notable people, who, as they step out of an aeroplane, have to face the battery of ZIP cameras and know that every moment, every gesture will be seen by millions of people. Politicians not only have to speak well, they now have to have what is called a 'ZIP personality'. Perhaps we can sympathize when Members of Parliament say that they do not want to be ZIPPED.

Depending upon the level of the students and the stage of sequencing of the cloze procedure, the teacher can propose a multiple choice selection for the meaning of the word 'zip' or can simply ask students what it means.

In considering all of the above factors on cloze text preparation, the 
teacher thus sequences cloze exercises by moving from relatively simple to more difficult types.

\section{Text Presentation}

Rankin (1977) suggests the following sequencing for the presentation and use of the cloze procedure in the teaching of reading: the use of aural cloze, aural-visual cloze and finally conventional visual cloze. In aural cloze, the teacher, stopping at all blanks, reads a brief cloze text aloud to the students who do not have the cloze sheet but only a numbered page. As the teacher comes upon each blank, a numbered 'beep' is pronounced, and the students write what they think the deleted word is. The teacher repeats as often as necessary, providing prompts in the form of facial and vocal cues and/or pictures. In aural-visual cloze, the students have the cloze text in front of them, and the teacher proceeds as in aural cloze. The students follow the text silently, writing in the missing words. In conventional visual cloze, the students read silently and are asked to supply words for the mutilated texts from memory. They are directed to read through the entire passage before recording their answers.

In all three forms of cloze, discussion afterwards is crucial. The students offer reasons for their choices of particular words. The teacher acts as resource person and guide at this time. The process of discovering why an answer is correct is as important as the answer itself (Rye, 1982: 15). After discussion, in all three forms of cloze, the teacher distributes the original unmutilated text so that the students can compare their answers with the originals. At this point, the teacher begins training the students in the recognition of different context cues by repeatedly pointing out those cues which immediately surround the blank as well as those which may appear at the beginning, middle or end of a text. ${ }^{3}$ The teacher also trains students in guessing meaning from context, in clustering information and in confirming or rejecting predictions. At the same time, the teacher leads students to understand that this training will be useful to them in their independent reading. The teacher has an active, directive role and is not only increasing the face validity of the cloze procedure but is also acknowledging the role of the students' prior knowledge, both of which tend to increase reader confidence.

\section{Conclusion}

The use of the cloze procedure when it is carefully sequenced in presentation and when texts are meticulously selected and prepared by the teacher can be an effective teaching technique in the development of reading strategies and reading comprehension. However, the teacher should be aware of the fact that it is not more effective than other conventional 
techniques in wide use (Jongsma, 1980: 6). It is a viable technique among many.

\section{NOTES}

1. Scanning is a visual matching task in which the reader knows beforehand for what information he is looking and the form in which he will find it. He simply does not know where he will find it. He searches the page until he comes upon the date, name, reference etc. for which he is searching and quickly reads it. Then, he stops reading.

Search reading is a more advanced form of scanning in that the reader knows for what information he is looking but does not know the form it will take. It demands closer attention to the text for longer periods of time. For more details see Pugh (1979).

2. A strategy is here defined as a plan to achieve a goal.

3. See McCullough (1958) and Emans (1969) for the classification and recognition of context cues.

\section{REFERENCES}

Bachman, Lyle F. (1985). Performance on cloze tests wih fixed-ratio and rational deletions. TESOL, 19(3), 535-556.

Bortnick, Robert and G.S. Lopardo. (1973). An instructional application of the cloze procedure. Journal of Reading, 16, 296-300.

Emans, Robert. (1969). Use of context clues. In J. Allen Figurel (ed.), Reading and Realism. Newark, Delaware: International Reading Association.

Grellet, Francoise. (1981). Developing Reading Skills. Cambridge: Cambridge University Press.

Hoffman, J.V. (1980). Studying contextual build-up during reading through cumulative cloze. Journal of Reading Behavior 12(4), 337-341.

Jongsma, E.A. (1971). The Cloze Procedure as a Teaching Technique. Newark, Delaware: International Reading Association.

- (1980). Cloze Instruction Research: A Second Look. Newark, Delaware: International Reading Association.

McCullough, Constance M. (1958). Context aids in reading. Reading Teacher 11(4), 225-229.

Marino, Jacqueline. (1981). Cloze passages: guidelines for selection. Journal of Reading, March 479-483.

Pugh, A.K. (1979). Silent Reading. Heinemann.

Rankin, E.F. (1977), Sequence strategies for teaching reading comprehension with the cloze procedure. In P. David Pearson and Jane Hansen (eds.) Reading: Theory, Research and Practice, 26th Yearbook of the National Reading Conference. Newark, Delaware: International Reading Association.

Rye, James. (1982). Cloze Procedure and the Teaching of Reading. London: Heinemann. 
Taylor, Wilson. (1953). Cloze procedure: a new tool for measuring readability. Journalism Quarterly, 30, 415-433.

Van Parreren, C.F. and M.C. Schouten-Van Parreren. (1981). Contextual guessing: a trainable reader strategy. System, 9(3), 235-241.

Weaver, Wendell W. (1965). Theoretical aspects of the cloze procedure. In E.L. Thurston and L.E. Hafner (eds.) The Philosophical and Sociological Bases of Reading, 19th Yearbook of the National Reading Conference. Newark, Delaware: International Reading Association.

\section{THE AUTHOR}

Patricia Raymond is a language teacher at the Centre for Second Language Learning of the University of Ottawa. She holds a B.A. (French) from Rutgers, a licence and a maitrise (anglais) from the Sorbonne, and an M.A. (Linguistics) from Ottawa University. She teaches ESL courses in the Faculty of Arts as well as graduate seminars in reading and writing in a second language in the Faculty of Education. She is a Ph.D. student at the University of Montreal. 